\title{
Pharmacoeconomic evaluations of CDK4/6 inhibitors plus endocrine therapy for advanced hormone receptor-positive (HR+) and human epidermal growth factor receptor-2 negative (HER2-) breast cancer: a systematic review
}

\author{
Linhui Zhu ${ }^{1,2 \#}$, Mengmeng Wang ${ }^{1,2 \#}$, Xin Luo ${ }^{1,2}$, Huan $\mathrm{Li}^{1,2}$, Han Shan ${ }^{1,2}$, Qiong Du ${ }^{1,2}$, Qing Zhai ${ }^{1,2}$ \\ ${ }^{1}$ Department of Pharmacy, Fudan University Shanghai Cancer Center, Shanghai, China; ${ }^{2}$ Department of Oncology, Shanghai Medical College, \\ Fudan University, Shanghai, China \\ Contributions: (I) Conception and design: L Zhu, M Wang; (II) Administrative support: Q Du, Q Zhai; (III) Provision of study materials or patients: \\ X Luo, L Zhu; (IV) Collection and assembly of data: H Li, M Wang; (V) Data analysis and interpretation: H Shan, L Zhu, M Wang; (VI) Manuscript \\ writing: All authors; (VII) Final approval of manuscript: All authors. \\ \#These authors contributed equally to this work. \\ Correspondence to: Qiong Du; Qing Zhai. Department of Pharmacy, Fudan University Shanghai Cancer Center, Shanghai, China; Department of \\ Oncology, Shanghai Medical College, Fudan University, Shanghai 200032, China. Email: dujoan-88@163.com; zhaiqing63@126.com.
}

Background: Hormone receptor-positive $(\mathrm{HR}+)$ and human epidermal growth factor receptor-2 negative (HER2-) breast cancer is the most common molecular subtype of breast cancer in many countries, and endocrine therapy remains a mainstay in its treatment. Cyclin-dependent kinase (CDK) 4/6 inhibitors are a new class of targeted agents administered orally that are recommended being used in combination with endocrine therapy as first and second line treatments for advanced HR+/HER2- breast cancer. However, their high prices largely hinder using these drugs in real world settings. To offer a new basis for future research, we investigated the cost-effectiveness of combinations of CDK4/6 inhibitors with endocrine therapy in the treatment of advanced HR+/HER2- breast cancer.

Methods: We systematically searched several frequently used databases and identified economic evaluations published from February 2015 to April 2021. The systematic review was performed after retrieving the literatures and extracting data based on inclusion and exclusion criteria. The quality of each selected economic evaluation was assessed by the Consolidated Health Economic Evaluation Reporting Standards (CHEERS).

Results: The literature search yielded 161 articles, among which fourteen studies (15 articles) with CHEER scores ranging from $58.33 \%$ to $87.50 \%$ entered the final analysis. Markov models were used in most studies. Based on the currently available data, CDK4/6 inhibitors plus endocrine therapy were less costeffective in first- or second-line treatment of patients with HR+/HER2- advanced breast cancer. However, ribociclib plus letrozole was more cost-effective than palbociclib plus letrozole in the first-line treatment of postmenopausal women. The economic impacts of CDK4/6 inhibitors plus endocrine therapy in nonpostmenopausal patients or second-line therapy cannot be fully evaluated due to the limited number of studies. The three most common factors affecting economic outcomes were the prices of CDK4/6 inhibitors, hazard ratios for progression-free survival and overall survival, and health status utility values.

Discussion: CDK4/6 inhibitors plus endocrine therapy have shown significantly improved efficacy outcomes in HR+/HER2 - metastatic breast cancer (mBC)/advancer breast cancer (ABC) first-line and second-line treatment for endocrine-sensitive and endocrine-resistant populations, while more potential fields including neoadjuvant and adjuvant settings are being identified to benefit a wider range of breast cancer patients. Meanwhile, risk of severe adverse events that more likely to happen in patients treated with CDK4/6 inhibitors can lead to reduced life quality and higher medical costs patients need to afford. The adverse drug reaction related cost in several economic burden studies were explored to be primarily driven by hospitalizations and outpatient, and assessment of cost associated with CDK4/6 inhibitors adverse events 
is worth further developing. Drug wastage costs were found higher in palbociclib regimen than ribociclib regimen due to different dosing patterns. Moreover, current economic evaluations showed that ribociclib plus letrozole had better economic benefits than palbociclib plus letrozole for first-line treatment of postmenopausal women with HR+/HER2- ABC.

Keywords: CDK4/6 inhibitors; breast cancer; pharmacoeconomic evaluation; systematic review

Submitted Jul 16, 2021. Accepted for publication Dec 24, 2021.

doi: $10.21037 / \mathrm{atm}-21-5110$

View this article at: https://dx.doi.org/10.21037/atm-21-5110

\section{Introduction}

According to the latest global cancer burden data released by the World Health Organization's International Agency for Research on Cancer, the number of new breast cancer (BC) cases was 2.26 million in 2020, which means BC was the most prevalent cancer worldwide (1). Hormone receptor-positive $(\mathrm{HR}+)$ and human epidermal growth factor receptor-2 negative (HER2-) breast cancer is the most common molecular subtype of breast cancer in many countries (2), and endocrine therapy remains a mainstay in its treatment. The prognosis of patients with advanced HR+/HER2 - breast cancer usually depends on the sensitivity to endocrine therapy (SET), and patients with resistance to endocrine therapy often have a poor prognosis after disease progression due to insufficient effective treatment strategies (3). New therapeutic agents are being developed to prolong the survival of such patients, among which the cyclin-dependent kinase inhibitors (CDKi), a group of novel orally-administered targeted drugs, have become a global research hotspot in recent years.

Cyclin-dependent kinases (CDKs) are serine/threonine kinases that bind to cyclin to control the whole cell cycle, and they are regarded as key regulatory enzymes through the cell cycle (4). Overexpression of functional mutations of CDKs and cyclins, and deletion or dysfunction of CDK inhibitory factors can lead to dysregulation of CDK activity, which in turn can cause a disordered cell cycle and lead to malignant tumors (5). Therefore, CDK inhibitors have been considered novel agents for cancer therapy. Three generations of CDK inhibitors have been developed up to now, and among them the first two generations of CDK inhibitors could not be clinically applied due to their poor selectivity against CDK and high toxicity. The thirdgeneration of CDK inhibitors can specifically inhibit CDK4/6 targets and become the first kind of selective CDK inhibitors licensed for clinical use (6). The mechanism of CDK4/6 inhibitors is to inhibit the phosphorylation of tumor suppressor retinoblastoma protein $(\mathrm{Rb})$ by preventing CDK4/6 from binding to cyclinD. Further, these drugs inhibit the expression of the $\mathrm{Rb}$-mediated transcriptional elongation factor $\left(\mathrm{E}_{2} \mathrm{~F}\right)$ family, preventing cells from proliferating through the G1/S checkpoint $(7,8)$. The CDK4/6-Rb axis plays an extraordinarily important role in ER+ breast cancer, where the binding of estrogen to the estrogen receptor promotes cyclinD1 transcription, activating $\mathrm{Rb}$ phosphorylation and CDK4/6 to complete the entire cell cycle (9). It has been reported that overexpression of cyclinD 1 was observed in approximately $50 \%$ of breast cancer cases $(8,10)$. Therefore, CDK4/6 inhibitors plus endocrine therapy have shown satisfactory efficacy in patients with advanced $\mathrm{HR}+$ breast cancer by inhibiting cyclinD1 and CDK4/6. Clinical trials have demonstrated that CDK4/6 inhibitors did significantly improve survivals in these patients.

CDK4/6 inhibitors plus endocrine therapy are primarily indicated for advanced breast cancer (ABC) or metastatic breast cancer (mBC) as target population (11). In 2018, palbociclib was approved by the Chinese National Medical Products Administration (NMPA) for treating HR+/HER2$\mathrm{ABC} / \mathrm{mBC}$. In 2020, abemaciclib was approved for treating $\mathrm{HR}+/ \mathrm{HER} 2-\mathrm{ABC} / \mathrm{mBC}$. The combination of CDK4/6 inhibitors with endocrine therapy was also included in the Chinese Society of Clinical Oncology (CSCO) guidelines as a treatment recommendation for such patients, confirming the effectiveness of CDK4/6 inhibitor regimens. At present, CDK4/6 inhibitors have not been approved into the Catalogue of Drugs for Basic National Medical Insurance, so that patients have to afford CDK4/6 inhibitors at their own expenses completely. Even with the support of some social charity projects, most Chinese patients are still under great pressure on large expenses, which hinders using these drugs in real-world settings to a great extent. Therefore, 
economic evaluations of CDK4/6 inhibitors plus endocrine therapy are urgently required in order to find better therapy regimens and provide evidences for government health insurance decision-making. Here we systematically reviewed the pharmacoeconomic evaluations of CDK4/6 inhibitors plus endocrine therapy in Chinese- and Englishlanguage literatures, to clarify the economic properties of the combinations of CDK4/6 inhibitors with endocrine therapy in treating advanced HR+/HER2- breast cancer and offer a new basis for subsequent economic researches. We presented the following article in accordance with the PRISMA reporting checklist (available at https://atm. amegroups.com/article/view/10.21037/atm-21-5110/rc).

\section{Methods}

\section{Literature search}

We systematically searched Chinese-language databases including China National Knowledge Infrastructure, Wanfang Database, and CQVIP, and English-language databases including PubMed, ScienceDirect, and Web of Science by using Chinese and English keywords or subject words including CDK4/6 inhibitor, advanced breast cancer, palbociclib, ribociclib, abemaciclib, pharmacoeconomics, economic evaluation, cost, cost-effectiveness, cost-benefit, and cost-utility. Since the first CDK4/6 inhibitor palbociclib was marketed in the United States in February 2015, the search period was set from February 2015 to April 2021.

\section{Inclusion and exclusion criteria}

\section{Inclusion criteria}

The inclusion criteria included: (I) the subjects were patients with advanced HR+/HER2- breast cancer; (II) the intervention regimens included a CDK4/6 inhibitor; (III) the outcome indicators included cost, life-years (LYs), quality-adjusted life-years (QALYs), incremental costeffectiveness ratio (ICER), and incremental cost-utility ratio (ICUR); and (IV) the study type was pharmacoeconomic evaluation through the modeling-based approach.

\section{Exclusion criteria}

The exclusion criteria were: (I) articles only with abstract but without access to the full text; (II) reviews or commentaries; (III) literatures with incomplete or erroneous data; (IV) duplicate publications; (V) literatures published in languages other than Chinese or English; (VI) literatures that do not specify outcome indicators; (VII) literatures containing only cost analysis or budget impact analysis; (VIII) literatures that analyze only the efficacy or pharmacological effects of CDK4/6 inhibitors.

\section{Data extraction}

The extracted data included: (I) author(s) and year of publication; (II) country; (III) study perspective; (IV) target population; (V) type of study; (VI) time horizon; (VII) discount rate; (VIII) evaluation model; (IX) intervention regimen; (X) control regimen; (XI) cost type; (XII) outcome measures; (XIII) ICER and ICUR; (XIV) willingness to pay (WTP) threshold; (XV) sensitivity analysis; (XVI) conclusions.

\section{Quality evaluation of the articles}

The quality of the included studies was evaluated by the Consolidated Health Economic Evaluation Reporting Standards (CHEERS) $(12,13)$, which focuses on six aspects of a pharmacoeconomic evaluation report: title and abstract, introduction (background and objective), methods, results, discussion, and others (funding sources and conflicts of interest). Each item was scored following the compliance with the CHEERS (full compliance $=1$, partial compliance $=0.5$, and non-compliance $=0$ ). The total score of the report was calculated using the following formula: total score = sum of the actual scores of all items/sum of all items when fully complied with $\times 100$. The quality of a report was regarded as high if the total score was $\geq 85 \%$, relatively high if $70-85 \%$, medium if $55-70 \%$, and low if $<55 \%$ (14).

\section{Results}

\section{Results of literature search and quality of the included literature}

After a comprehensive search based on the inclusion and exclusion criteria, a total of 15 articles (15-29) were included. Because the study by Matter-Walstra et al. was published as two articles (one with revised results) $(21,22)$, 14 studies entered the final analysis. The flowchart of article searching and screening is shown in Figure 1. The CHEERs scores of these 14 studies ranged from $58.33 \%$ to $87.50 \%$, suggesting these studies were of medium to high quality. 


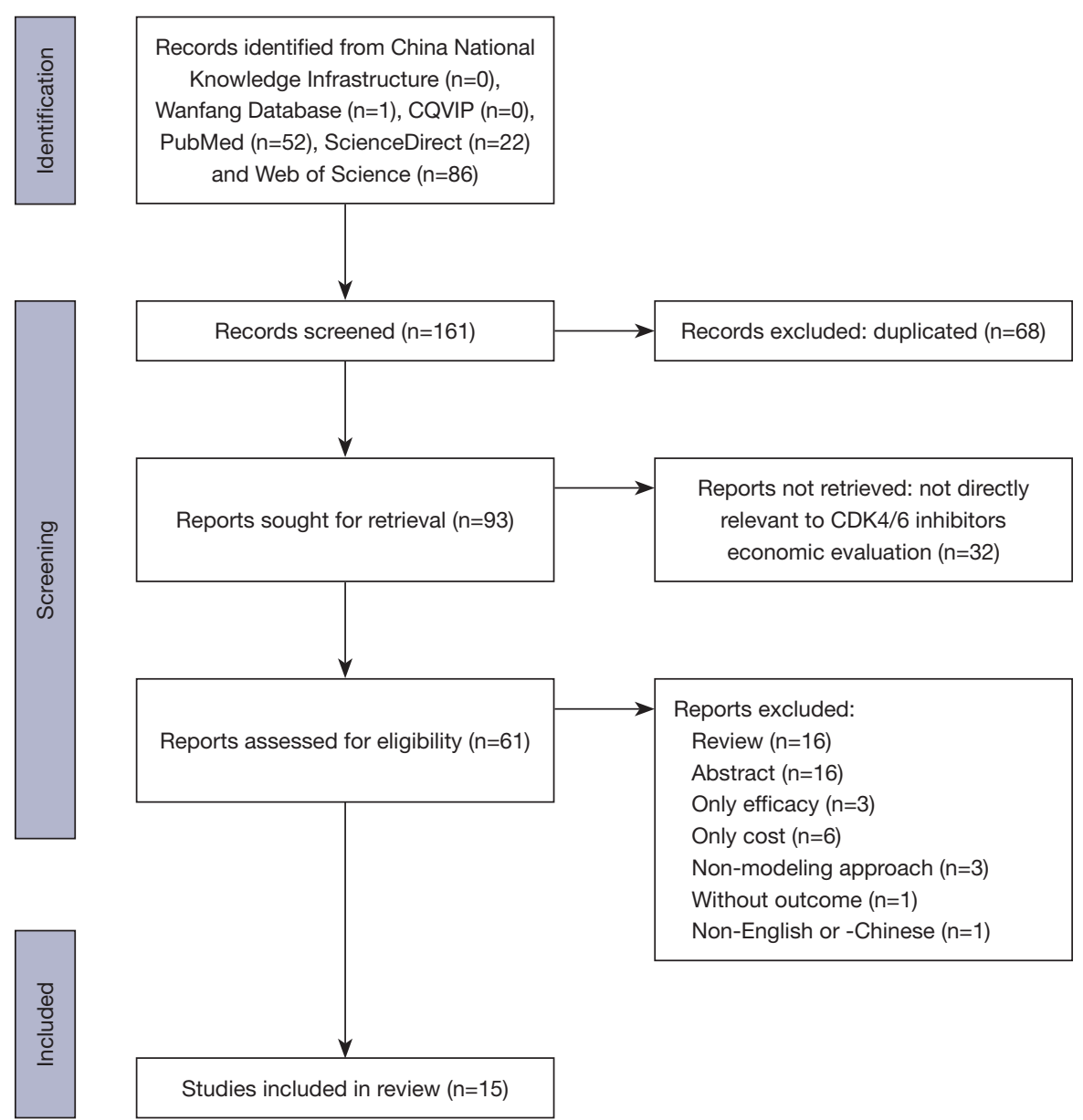

Figure 1 Flow chart of screening studies.

\section{Basic features of the enrolled studies}

The years of publication of the included studies ranged from 2016 to 2021. Eight studies were conducted in the United States $(18,20,23,25-29), 3$ in China $(24,26,28)$, and 1 each in Spain (15), the United Kingdom (16), Singapore (19), Canada (17), and Switzerland (21,22). One of the 14 studies did not describe the study perspective (25), 4 studies adopted a health system perspective $(15,19,21,22,24), 6$ studies used a health insurance payer perspective $(17,18,23,26,27,29), 1$ study used a society-wide perspective (20), and 2 studies used both a health system perspective and a health insurance payer perspective $(16,28)$. Study types included cost-effectiveness analysis (CEA) and/ or cost-utility analysis (CUA).

Target populations in all studies were HR+/HER2-
ABC. With poor disease progression and physical condition, these patients were eligible for CDK4/6 inhibitor treatment. One of these 14 studies did not report on the menopausal status of the target population (26), three studies were conducted in non-postmenopausal patients $(19,27,28)$, and the remaining 10 studies evaluated the cost-effectiveness of using CDK4/6 inhibitors plus endocrine therapy in postmenopausal women (15-18,20-25,29). In terms of treatment line, two studies did not report the treatment line $(18,25)$, and only three studies assessed the cost-effectiveness of CDK4/6 inhibitors plus endocrine therapy for second-line treatment in target populations $(20,26,29)$.

Since all included studies were pharmacoeconomic evaluations through a modeling-based approach, the study 
time horizon was generally as long as possible to simulate long-term outcomes in the target population after receiving the intervention. Only three of the included studies explained the reason for selecting their study time horizon, all of which were sufficiently long to capture most survival events in the target patients $(15,17,19)$. Eight studies chose specific periods, including 10 years $(18,19,26,29), 15$ years $(15,17)$, and 40 years $(16,23)$, as time horizons, while six studies used full lifetime to simulate the costs and health outputs of patients following using CDK4/6 inhibitors $(20-22,24,25,27,28)$. Most studies consistently discounted the costs and health outcomes consistently at $3 \%$ or $5 \%$ (15,17-20,23-29), except for one study that did not report a discount rate (16) and one study that used both $3 \%$ and $6 \%$ discount rates for costs and health outputs $(21,22)$.

The basic information of the included studies is summarized in Table 1.

\section{Results of economic evaluations}

The results of economic evaluations are summarized in Table 2.

\section{Evaluation models}

Breast cancer is a chronic disease that usually involves multiple survival states, including progression-free survival (PFS) (partial remission and complete remission), progression-disease survival, and death. Model analysis is more suitable for the complete simulation of breast cancer patients' costs and health outcomes throughout their life cycle. Four of the included studies used partitioned survival models $(15,16,19,23)$, three used discrete event simulation models $(17,20,24)$, and seven used Markov models (18,21,22,25-29). Markov model fits to chronic diseases, which is one of the basic models in economic evaluations of cancer field. However, since the Markov model exhibits certain disadvantages, including the complexity to calculate the transition probability, presence of multiple hypothetical events, and deviation from the real-world treatment, the partitioned survival model and discrete event simulation model are more suitable for the economic evaluation of metastatic tumors with more transitions in survival status.

\section{Intervention regimens versus control regimens}

The 14 included studies involved two comparisons: comparisons between CDK4/6 inhibitors plus endocrine therapy and endocrine therapy alone; and comparisons between different combinations of CDK4/6 inhibitors with endocrine therapy. The former included 12 studies, with the control regimens mainly including letrozole (17,20-25), fulvestrant $(18,20,26,29)$, and combinations with endocrine therapy $(19,27,28)$. The latter included three studies $(15,16,23)$ comparing the cost-effectiveness differences between ribociclib plus letrozole and palbociclib plus letrozole. No literature has evaluated the economic aspects of abemaciclib.

\section{Cost types and outcome measures}

The cost types of all studies were direct medical costs, which mainly included costs related to medications, adverse reactions management, medical tests, and supportive care after disease progression, in line with the study perspective of most studies. However, one study based on a societywide perspective did not consider direct non-medical costs and indirect costs when calculating the costs (20). CUA was adopted in all included studies, with the outcome indicators including cost, QALYs, and incremental cost-to-utility ratio (ICUR). CEA was also used in some articles for economic evaluation $(15,18,19,24,26-28)$, with the outcome indicators including cost, LYs, and incremental cost-to-effect ratio (ICER). All studies judged whether CDK4/6 inhibitors had clear economic benefits by comparing willingness-topay (WTP) thresholds [delineated according to national guidelines for economic evaluation and gross domestic product (GDP) per capita] with ICUR.

\section{Results of basic evaluation of cost-effectiveness}

The main conclusions from the 13 foreign studies were as follows: (I) CDK4/6 inhibitors plus endocrine therapy for first- or second-line treatment of patients with HR+/HER2$\mathrm{ABC}$ are less likely to be cost-effective from the societywide, health care system, and health care payer perspectives $(17-23,25,26,28,29)$. Only the study by Le et al. concluded that when used as the first-line treatment of HR+/HER2$\mathrm{ABC}$ in premenopausal and perimenopausal women, ribociclib plus endocrine therapy was more economically advantageous compared with endocrine therapy alone from the perspective of US health insurance payer (27). The economic advantage of a specific intervention regimen depends on various factors, including the type of CDK4/6 inhibitor, drug price, threshold setting, GDP per capita, and health care system. However, economically, CDK4/6 inhibitor plus endocrine therapy is unlikely to replace conventional endocrine therapy. (II) All the three studies evaluating the economic benefits among different CDK4/6 inhibitors concluded that ribociclib plus letrozole was more 


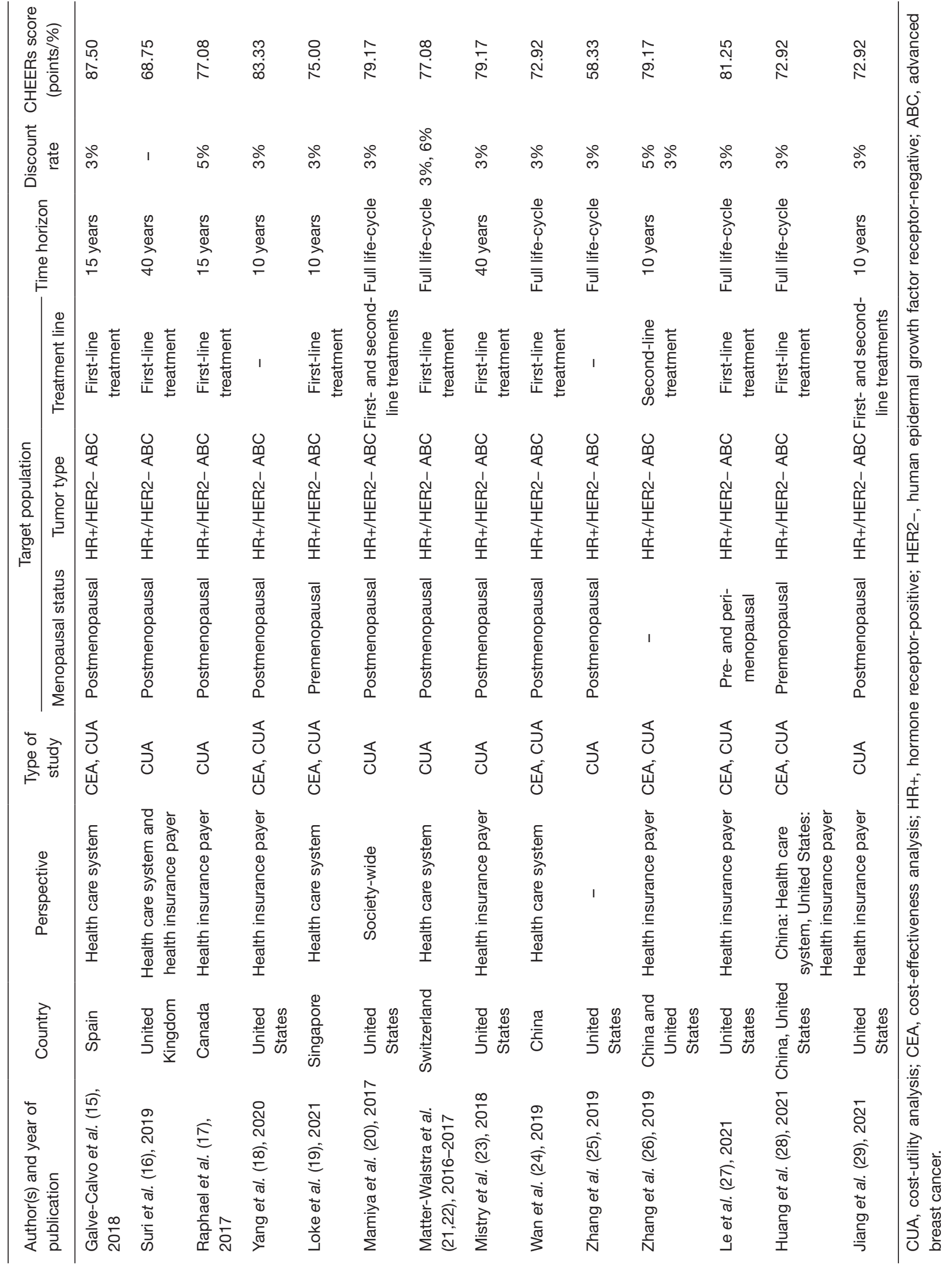




\begin{tabular}{|c|c|c|c|c|c|c|c|c|c|}
\hline $\begin{array}{l}\text { Author(s) } \\
\text { and year of } \\
\text { publication }\end{array}$ & $\begin{array}{c}\text { Evaluation } \\
\text { model }\end{array}$ & $\begin{array}{l}\text { Intervention } \\
\text { regimen }\end{array}$ & $\begin{array}{l}\text { Control } \\
\text { regimen }\end{array}$ & Cost type & Outcome measures & ICER ICUR & $\begin{array}{l}\text { Willingness-to-pay } \\
\text { threshold }\end{array}$ & Sensitivity analysis & Conclusions \\
\hline $\begin{array}{l}\text { Galve-Calvo } \\
\text { et al. (15), } \\
2018\end{array}$ & $\begin{array}{l}\text { Partitioned } \\
\text { survival model }\end{array}$ & $\begin{array}{l}\text { Ribociclib plus } \\
\text { letrozole }\end{array}$ & $\begin{array}{l}\text { Palbociclib } \\
\text { plus } \\
\text { letrozole }\end{array}$ & $\begin{array}{l}\text { Direct medical costs; } \\
\text { incremental cost: } € 439.86\end{array}$ & $\begin{array}{l}\text { LYs: incremental effectiveness: } 0.437 \text { LYs; QALY: } \\
\text { incremental effectiveness: } 0.285 \text { QALYS }\end{array}$ & $€ 1,007.69 / L Y ; € 1,543.62 / \mathrm{QALY}$ & $€ 20,000-30,000 / Q A L Y$ & $\begin{array}{l}\text { DSA: key drivers: parametric distribution } \\
\text { of PFS and OS, prices of ribociclib and } \\
\text { palbociclib, and time frame } \\
\text { PSA }\end{array}$ & The ribociclib regimen is cost-effective \\
\hline $\begin{array}{l}\text { Suri et al. (16), } \\
2019\end{array}$ & $\begin{array}{l}\text { Partitioned } \\
\text { survival model }\end{array}$ & $\begin{array}{l}\text { Ribociclib plus } \\
\text { letrozole }\end{array}$ & $\begin{array}{l}\text { Palbociclib } \\
\text { plus } \\
\text { letrozole }\end{array}$ & $\begin{array}{l}\text { Direct medical costs; } \\
\text { incremental cost: }-£ 8,464\end{array}$ & QALYs: incremental effectiveness: 0.261 QALYs & $-£ 32,429.12 /$ QALY & $£ 30,000 /$ QLY & $\begin{array}{l}\text { DSA: key drivers: HR of PFS and OS for } \\
\text { palbociclib regimen and ribociclib regimens } \\
\text { compared to letrozole alone; discount rate } \\
\text { PSA }\end{array}$ & The ribociclib regimen is a preferred regimen \\
\hline $\begin{array}{l}\text { Raphael et al. } \\
\text { (17), } 2017\end{array}$ & $\begin{array}{l}\text { Discrete event } \\
\text { simulation } \\
\text { model }\end{array}$ & $\begin{array}{l}\text { Palbociclib } \\
\text { plus letrozole }\end{array}$ & Letrozole & $\begin{array}{l}\text { Direct medical costs; } \\
\text { Incremental cost: } \$ 161,507.58\end{array}$ & QALYs: incremental effectiveness: 14.68 QALMs & $\$ 10,999.16 /$ QALM & $\begin{array}{c}\$ 4,167 / \text { QALM } \\
(\$ 50,000 / \text { QALY })\end{array}$ & PSA & The palbociclib regimen is not cost-effective \\
\hline $\begin{array}{l}\text { Yang et al. } \\
(18), 2020\end{array}$ & Markov model & $\begin{array}{l}\text { Ribociclib + } \\
\text { fulvestrant }\end{array}$ & Fulvestrant & $\begin{array}{l}\text { Direct medical costs; } \\
\text { incremental cost: } \$ 382,172\end{array}$ & $\begin{array}{l}\text { LYs: incremental effectiveness: } 0.65 \text { Lys; QALYs: } \\
\text { incremental effectiveness: } 0.47 \text { QALYs }\end{array}$ & $\$ 587,956 / L Y ; \$ 813,132 / \mathrm{QALY}$ & $\$ 150,000 /$ QALY & $\begin{array}{l}\text { DSA: key drivers: utility value of PFS status } \\
\text { and price of ribociclib } \\
\text { PSA }\end{array}$ & The ribociclib regimen is not cost-effective \\
\hline $\begin{array}{l}\text { Loke et al. } \\
\text { (19), } 2021\end{array}$ & $\begin{array}{l}\text { Partitioned } \\
\text { survival model }\end{array}$ & $\begin{array}{l}\text { Ribociclib + } \\
\text { endocrine } \\
\text { therapy }\end{array}$ & $\begin{array}{l}\text { Endocrine } \\
\text { therapy }\end{array}$ & $\begin{array}{l}\text { Direct medical costs; } \\
\text { incremental cost: SGD90,470 }\end{array}$ & $\begin{array}{l}\text { LYs: incremental effectiveness: } 0.6323 \mathrm{LYs} ; \\
\text { QALYs: incremental effectiveness: } 0.4577 \text { QALYs }\end{array}$ & SGD143,080/LY; SGD197,667/QALY & SGD100,000/QALY & $\begin{array}{l}\text { DSA: key drivers: utility value of PFS status } \\
\text { and price of ribociclib } \\
\text { PSA }\end{array}$ & The ribociclib regimen is not cost-effective \\
\hline $\begin{array}{l}\text { Mamiya et al. } \\
\text { (20), } 2017\end{array}$ & $\begin{array}{l}\text { Discrete event } \\
\text { simulation } \\
\text { model }\end{array}$ & $\begin{array}{l}\text { Palbociclib } \\
\text { plus letrozole; } \\
\text { pallocicilib + } \\
\text { fulvestrant }\end{array}$ & $\begin{array}{l}\text { Letrozole; } \\
\text { fulvestrant }\end{array}$ & $\begin{array}{l}\text { Direct medical costs; } \\
\text { incremental cost: } \$ 244,326 \\
\text { (first-line), } \$ 114,591 \\
\text { (second-line) }\end{array}$ & $\begin{array}{l}\text { QALYs: incremental effectiveness: } 0.32 \text { QALY (first- } \\
\text { line); } 0.12 \text { QALY (second-line) }\end{array}$ & $\begin{array}{l}\$ 768,498 / \text { QALY (first-line); } \$ 918,166 / \\
\text { QALY (second-line) }\end{array}$ & $\$ 100,000 /$ QALY & $\begin{array}{l}\text { DSA: key drivers: utility value of each health } \\
\text { state, probability of choosing chemotherapy } \\
\text { as post-progression treatment, price of } \\
\text { palbociclib, and discount rate } \\
\text { PSA }\end{array}$ & $\begin{array}{l}\text { All the palbociclib regimens are not cost- } \\
\text { effective }\end{array}$ \\
\hline $\begin{array}{l}\text { Matter- } \\
\text { Walstra et al. } \\
(21,22), 2016- \\
2017\end{array}$ & Markov model & $\begin{array}{l}\text { Palbociclib } \\
\text { plus letrozole }\end{array}$ & Letrozole & $\begin{array}{l}\text { Direct medical costs; } \\
\text { incremental costs: CHF342,440 } \\
\text { (pre-revision), and post-revision } \\
\text { results not reported }\end{array}$ & $\begin{array}{l}\text { QALYS: incremental effectiveness: } 1.14 \text { QALYs } \\
\text { (pre-revision), and post-revision results not } \\
\text { reported }\end{array}$ & $\begin{array}{l}\text { CHF301,227/QALY (pre-revision); } \\
\text { CHF137,063/QALY }\end{array}$ & CHF100,000/QALY & $\begin{array}{l}\text { DSA: key drivers: utility values of PFS state } \\
\text { and HR of PFS and OS for palbociclib } \\
\text { regimen versus letrozole alone } \\
\text { PSA }\end{array}$ & The palbociclib regimen is not cost-effective \\
\hline $\begin{array}{l}\text { Mistry et al. } \\
\text { (23), } 2018\end{array}$ & $\begin{array}{l}\text { Partitioned } \\
\text { survival model }\end{array}$ & $\begin{array}{l}\text { Ribociclib plus } \\
\text { letrozole }\end{array}$ & $\begin{array}{l}\text { Letrozole; } \\
\text { palbociclib } \\
\text { plus } \\
\text { letrozole }\end{array}$ & $\begin{array}{l}\text { Direct medical costs; } \\
\text { incremental cost: } \$ 144,915 \\
\text { (letrozole), }-\$ 43,037 \\
\text { (palbociclib + letrozole) }\end{array}$ & $\begin{array}{l}\text { QALYs: incremental effectiveness: } 0.689 \text { QALYs } \\
\text { (letrozole), } 0.086 \text { QALYs (palbociclib + letrozole) }\end{array}$ & $\begin{array}{l}\$ 210,369 / \text { QALY (letrozole), }-\$ 500,430 \\
\text { (palbociclib + letrozole) }\end{array}$ & $\$ 5,000-200,000 /$ QALY & $\begin{array}{l}\text { DSA: key drivers: HR of PFS and OS for } \\
\text { palbociclib regimen and ribociclib regimen } \\
\text { versus letrozole alone, cost of PD state, } \\
\text { the utility value of disease response, and } \\
\text { discount rate } \\
\text { PSA }\end{array}$ & $\begin{array}{l}\text { Ribociclib regimen is not cost-effective } \\
\text { compared to letrozole alone but is superior to } \\
\text { the palbociclib regimen }\end{array}$ \\
\hline $\begin{array}{l}\text { Wan et al. } \\
(24), 2019\end{array}$ & $\begin{array}{l}\text { Discrete event } \\
\text { simulation } \\
\text { model }\end{array}$ & $\begin{array}{l}\text { Ribociclib plus } \\
\text { letrozole }\end{array}$ & Letrozole & $\begin{array}{l}\text { Direct medical costs; } \\
\text { incremental cost: } \$ 10,881 \\
\text { (China), } \$ 23,935 \text { (Beijing) }\end{array}$ & $\begin{array}{l}\text { LYs: incremental effectiveness: } 0.631 \text { LYs; QALYs: } \\
\text { incremental effectiveness: } 0.451 \text { QALYs }\end{array}$ & $\begin{array}{c}\$ 17,224 / L Y \text { (China), } \$ 37,932 / L Y \\
\text { (Beijing), } \$ 24,126 / \text { QALY (China), } \\
\$ 53,071 \text { (Beijing) }\end{array}$ & $\begin{array}{l}\$ 24,360 / \text { AALY (China), } \\
\$ 553,384 / \text { QALY } \\
\text { (Beijing) }\end{array}$ & PSA & $\begin{array}{c}\text { When RIB costs less than } \$ 721 \text { or } \$ 1,170 \text { per } \\
4 \text { weeks, there was a nearly } 90 \% \text { likelihood } \\
\text { that the RIB regimen is cost-effective } \\
\text { (threshold: } \$ 24,360 / Q A L \text { or } \$ 53,384 / \text { QLLY, } \\
\text { respectively) }\end{array}$ \\
\hline $\begin{array}{l}\text { Zhang et al. } \\
\text { (25), } 2019\end{array}$ & Markov model & $\begin{array}{l}\text { Palbociclib } \\
\text { plus letrozole; } \\
\text { ribociclib plus } \\
\text { letrozole }\end{array}$ & Letrozole & $\begin{array}{l}\text { Direct medical costs; } \\
\text { incremental cost: } \$ 304,510 \\
\text { (pallbociclib), } \$ 378,335 \\
\text { (ribociclib) }\end{array}$ & $\begin{array}{l}\text { QALYs: incremental effectiveness: } 0.48 \text { QALYs } \\
\text { (palbociclib); } 0.86 \text { QALYs (ribociclib) }\end{array}$ & $\begin{array}{l}\text { \$634,396/QALY (palbociclib); } \\
\text { \$439,924/QALY (ribociclib) }\end{array}$ & $\$ 100,000 /$ QALY & $\begin{array}{l}\text { DSA: key drivers: HR for death and } \\
\text { progression in palbociclib regimen group } \\
\text { and letrozole alone group and prices of } \\
\text { palbociclib and ribociclib }\end{array}$ & $\begin{array}{l}\text { The ribociclib and palbociclib regimens are } \\
\text { not cost-effective compared with letrozole } \\
\text { alone }\end{array}$ \\
\hline $\begin{array}{l}\text { Zhang et al. } \\
\text { (26), } 2019\end{array}$ & Markov model & $\begin{array}{l}\text { Palbociclib + } \\
\text { fulvestrant }\end{array}$ & Fulvestrant & $\begin{array}{c}\text { Direct medical costs; } \\
\text { incremental cost: } \$ 277,504 \\
\text { (United States), } \$ 112,974 / L Y \\
\text { (China) }\end{array}$ & $\begin{array}{c}\text { LYs: Incremental effectiveness: } 0.83 \text { LYs (United } \\
\text { States), } 0.912 \text { LYs (China); QALYs: incremental } \\
\text { effectiveness: } 0.568 \text { QALYs (United States), } 0.618 \\
\text { QALYs (China) }\end{array}$ & $\begin{array}{c}\$ 334,062 / L Y \text { (United States); } \\
\$ 123,925 / \text { LY (China); } \$ 488,854 / \text { QALY } \\
\text { (United States); } \$ 182,779 / \text { QALY } \\
\text { (China) }\end{array}$ & $\begin{array}{c}\$ 100,000 / Q A L Y \\
\text { (United States); } \\
\$ 26,846 \text { and } 58,480 / \\
\text { QALY (China) }\end{array}$ & $\begin{array}{l}\text { DSA: key drivers: HR of PFS for palbociclib } \\
\text { regimen versus letrozole alone, the utility } \\
\text { value of PFS state, and price of palbociclib } \\
\text { PSA }\end{array}$ & The palbociclib regimen is not cost-effective \\
\hline
\end{tabular}

Table 2 (continued) 
Table 2 (continued)

Author(s)

and year of
publication

Evaluation
model

Intervention
regimen

Control
regimen

Cost type

Outcome measures

ICER ICUR

Willingness-to-pay
threshold

Sensitivity analysis

Conclusions

Le et al. (27), Markov model

Ribociclib +

Endocrine

Direct medical costs;

LYs: incremental effectiveness: 3.63 LYS; QALYS:

$\$ 87,473 / L Y ; \$ 129,299 /$ QALY

$\$ 150,000 /$ QALY

DSA: key drivers: the price of ribociclib and utility value of PFS state

therapy

incremental effectiveness: 2.46 QALYS

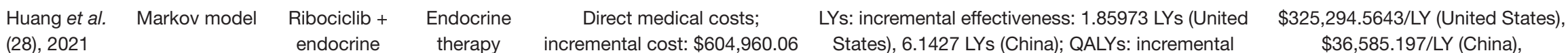
therapy effectiven 1427 LYs (China); QALYs: incrementa) (China)

$\$ 36,585.197 / L Y$ (China),

$\$ 150,000 /$ QALY 3.65686 QALYS (China)

$539,357.95 /$ QALY

$\$ 29,383 /$ QALY (Chin

$\$ 61,454.96 /$ QALY (China)

$\$ 150,000 /$ QALY

$\$ 1,073,526 /$ QALY

QALYs: incremental effectiveness: 0.327 QALYs

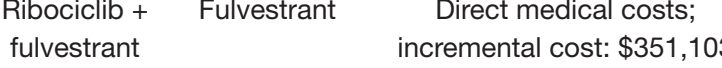

DSA: key drivers: the price of ribociclib and tility values of PD and PFS states

PSA

DSA: key drivers: the price of ribociclib and utility value of PFS state

(29), 202

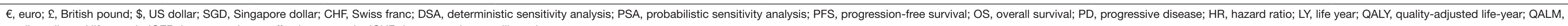
quality-adjusted life month; ICER, incremental cost-effectiveness ratio; ICUR, incremental cost-utility ratio. 
cost-effective than palbociclib plus letrozole as the first-line treatment of $\mathrm{HR}+/ \mathrm{HER} 2-\mathrm{ABC} / \mathrm{mBC}$ in postmenopausal women $(15,16,23)$, and even in two studies conducted by Mistry et al. and Suri et al. also concluded that the ribociclib regimen was superior to the palbociclib regimen $(16,23)$. Currently, there is no economic evaluation of secondline treatment for these two combinations. Economically, ribociclib plus letrozole is superior to palbociclib plus letrozole in the first-line settings.

One of the three Chinese studies evaluated the economic properties of palbociclib plus fulvestrant for the second-line treatment of patients with HR+/HER2- mBC and concluded that it was unlikely to be cost-effective (26). By establishing simulation models, the other two Chinese studies evaluated the cost effectiveness of ribociclib plus endocrine therapy, a CDK4/6 inhibitor not yet available in China, for the first-line treatment of HR+/HER2 - ABC in postmenopausal and premenopausal women, respectively, to inform the health insurance authorities on the pricing of this drug when it is marketed in China. Wan et al. used three times the per capita GDP of China $2016(\$ 24,360)$ and three times the per capita GDP of Beijing city 2016 $(\$ 53,384)$ as willingness-to-pay thresholds $(24)$. They found that ribociclib plus letrozole could be cost effective when the price of ribociclib was below $\$ 732$ and $\$ 1,170$ per 4 weeks for China and Beijing, respectively (24). Huang et al. concluded that a value-based price for the cost of ribociclib was less than $\$ 31.74 / 200 \mathrm{mg}$ for China (in 2018, the three times per capita GDP was \$29,383/QALY in China) (28).

\section{Sensitivity analysis}

All studies conducted sensitivity analyses to verify the robustness of the base analyses, mostly using both univariate sensitivity analysis and probabilistic sensitivity analysis. Two studies conducted only probabilistic sensitivity analysis $(17,24)$ and one study conducted only univariate sensitivity analysis (25). The key drivers addressed in the univariate sensitivity analysis were mainly the price of CDK4/6 inhibitors (15,18-20,25-29), discount rate $(16,20,23)$, study time horizon (15), hazard ratios (transition probability) of PFS and overall survival (OS) $(16,21-23,25,26)$, parametric distribution of PFS and OS (15), utility values under different health states (18-23,26-29), and treatment cost after disease progression (23). The three most frequently mentioned factors affecting the cost-effectiveness were the price of CDK4/6 inhibitors, hazard ratios of PFS and OS, and utility values under different health conditions.
Probabilistic sensitivity analyses were mostly implemented using Monte Carlo simulation, using cost-effectiveness planes or cost-effectiveness acceptability curves (CEACs) to represent the likelihood that a CDK4/6 inhibitor regimen is cost-effective at the current willingness-to-pay threshold in each country. The included studies validated the robustness of the models by using probabilistic sensitivity analysis. Two studies compared the economic benefits between two CDK4/6 inhibitors and concluded by a probabilistic sensitivity analysis that ribociclib plus letrozole is more costeffective than palbociclib plus letrozole regardless of the willingness-to-pay thresholds $(16,23)$. These results further confirmed that ribociclib plus letrozole is a superior regimen over palbociclib plus letrozole.

\section{Discussion}

In most economic evaluations of CDK4/6 inhibitors plus endocrine therapy, models are constructed to analyze the costs and health outcomes in breast cancer patients throughout the life cycle and further calculate the incremental cost and effectiveness. With the advances in CDK4/6 inhibitor related researches, the economic evaluation of CDK4/6 inhibitors plus endocrine therapy will undoubtedly involve more treatment regimens and therapeutic purposes and the results may vary spontaneously.

As the $\mathrm{CDK} 4 / 6-\mathrm{Rb}$ axis was proved to play the important role in cell cycle progression in estrogen receptor-positive breast cancer, CDK4/6 inhibitors have extraordinarily strong effect on HR+/HER2- advanced breast cancer $(\mathrm{ABC})$ patients combined with endocrine therapy in first line and second line treatment through clinical trials demonstration $(9,30)$. Based on outstanding survival benefits in HR+/HER2- ABC, CDK4/6 inhibitors have been triggered broader exploration in the localized and early breast cancer setting, including neoadjuvant and adjuvant studies (31-33). Considering neoadjuvant therapy, currently in National Comprehensive Cancer Network (NCCN) 2021 breast cancer guideline, recommended neoadjuvant therapy for HER2- BC is still chemotherapy regimen (NCT), and neoadjuvant endocrine therapy (NET) may be only considered for patients with ER+ disease or low-risk luminal biology. However, HR+/ HER2 - BC subtype was supposed to be less sensitive to NCT with respect to other subtypes, while NET turned into an equally effective and less toxic alternative to NCT through proof by multiple clinical trials $(34,35)$. 
Accordingly, concurrent neoadjuvant chemotherapy and estrogen deprivation had been proposed that whether NCT plus NET can convert to a higher tumor response. Several studies found that the combination neoadjuvant therapy appeared to improve the clinical response or shrinkage of tumor in ER+/HER2 - BC (36-38), while inconsistent conclusion was reached that NCT plus NET as neoadjuvant therapy was not superior to NCT or NET alone in tumor response $(39,40)$. More large-scale and high-quality prospective studies are required to follow these preliminary results to confirm the efficacy, safety and economic benefits of concurrent neoadjuvant chemotherapy and estrogen deprivation for HR+/HER2- BC patients, while in the future similar studies can involve CDK4/6 inhibitors into NET regimen to explore new fields. Besides, CDK4/6 inhibitors post-progression choice, combination partner and biomarker are also key questions many studies focus on to achieve deeper understanding on molecular mechanisms $(9,41)$. At present CDK4/6 inhibitors have exactly shown satisfactory efficacy on HR+/HER2- ABC, so more potential fields are being identified to benefit a wider range of breast cancer patients.

CDK4/6 inhibitors plus endocrine therapy have shown significantly improved efficacy outcomes in HR+/ HER2 - mBC/ABC first-line and second-line treatment $(11,42)$. For endocrine-sensitive population, clinical trials (palbociclib: PALOMA-2; ribociclib: MONALEESA-2, MONALEESA-3, MONALEESA-7; abemaciclib: MONARCH-3) found that palbociclib, ribociclib and abemaciclib plus letrozole or fulvestrant all obtained significantly longer PFS than endocrine therapy alone in clinical trials (43-47). While in two trials that reported OS data, MONALEESA-3 trial discovered that ribociclib plus fulvestrant and fulvestrant alone existed no significant differences (48) and as the only trial focusing on pre-/ perimenopausal population, MONALEESA-7 reported that ribociclib plus endocrine therapy showed notably longer OS than endocrine therapy alone (49). Based on the current studies, CDK4/6 inhibitors combined with endocrine therapy can benefit endocrine-sensitive $\mathrm{HR}+$ / HER2 - mBC/ABC population, while in the future longterm follow-up data of palbociclib and abemaciclib are worth the wait. For endocrine-resistant population, CDK4/6 inhibitors plus endocrine therapy similarly live up to common expectations. PALOMA-3 subgroup analysis showed that the preset statistical difference in PFS and OS had not reached between palbociclib plus fulvestrant and fulvestrant alone for HR+/HER2- mBC patients resistant to previous hormonal therapy $(50,51)$. Different from the negative outcomes of palbociclib, MONALEESA-3 and MONARCH-2 trial found that ribociclib plus fulvestrant and abemaciclib plus fulvestrant resulted in a significant PFS and OS improvement in $\mathrm{HR}+1$ HER2 - ABC patients resistant to previous endocrine therapy $(45,48,52,53)$. Schettini et al. conducted a metaanalysis to assess the efficacy of first-/second-line endocrine therapies \pm target therapies in clinically-relevant subgroups of HR+/HER2 - mBC (54). They found that for endocrinesensitive subgroup CDK4/6i-containing therapy had both the greatest PFS benefit and the numerically highest OS benefit, and for endocrine-resistant subgroup the CDK4/6i-containing therapy was the only group showing an individually significant pooled OS result. Concordantly, Messina et al. concluded that the addition of CDK4/6 inhibitors to endocrine therapy was associated with a statistically significant PFS and objective response rates (ORR) benefit in endocrine-sensitive and endocrineresistant setting for HR+/HER2- ABC (55), but meanwhile the use of CDK4/6 inhibitors plus endocrine therapy was characterized by a higher risk of G3-G4 adverse events than endocrine therapy alone. Clinical trials demonstrated that there was higher incidence of grade 3-4 hematologic adverse events with both ribociclib and palbociclib, while gastrointestinal-related toxicity appeared to be more predominant with abemaciclib $(10,56)$. Risk of severe adverse events that more likely to happen in patients treated with CDK4/6 inhibitors can lead to reduced life quality and higher medical costs patients need to afford, which may influence actual selection on CDK4/6 inhibitors in medical practice.

As newly marketed targeted drugs that have not yet been covered by national health insurance, their costs are extremely high. About CDK4/6 inhibitors, all economic evaluations included in our study just calculated direct medical costs, of which the drug treatment costs and adverse drug reaction related costs were indeed two major parts most studies focused on. The cost of drug treatment was mostly based on drug unit price and treatment frequency, and the drug unit price mainly came from the ex-factory price, wholesale acquisition costs and certain official websites or databases. The adverse drug reaction related cost was mostly obtained from management unit price and adverse reaction frequency in clinical trials, while management unit price in most studies were accessed from current literatures on economic burden of drug adverse events. Several economic burden studies explored that the primary driver of adverse events related costs in 
patients with $\mathrm{mBC}$ was associated with hospitalizations and outpatient (57-59). Severity and frequency of adverse events, targeted therapies were also mentioned as driver of adverse events related costs in mBC patients (60-62). However, most studies focused on the adverse events caused by chemotherapy and endocrine therapy, and currently the economic burden research on CDK4/6 inhibitor containing therapy has not been published. Therefore, assessment of cost associated with CDK4/6 inhibitors adverse events is worth developing in the future.

Many economic evaluations have truly concluded that CDK4/6 inhibitors combined with endocrine therapy are unlikely to be more cost-effective than endocrine therapy alone. Several studies have conducted cost analyses of CDK4/6 inhibitors. Two real-world cost analyses in the United States have shown that the cost of palbociclib contains high drug wastage costs. Li et al. found that $411(33.1 \%)$ of the 1,242 patients who used palbociclib changed dose, among whom 128 (31.1\%) experienced prescription fill overlap (average $=11.1$ days). The mean potential drug wastage cost among patients with fill overlap was $\$ 5,471$ (63). Based on a database, Dalal et al. retrospectively analyzed the impact of dosing modality on the cost of palbociclib. Dose modification was observed in $17.8 \%, 31.2 \%$, and $35.0 \%$ of patients in the first, second, and third lines. The average overlap in prescription fills was 9.2, 9.9, and 5.4 days in the first, second, and third line. This potential drug waste resulted in an average cost of $\$ 4,376, \$ 4,740$, and $\$ 2,592$ per patient in the first, second, and third line (64). The investigators attributed this to the fact that palbociclib is available in 125,100 , and $75 \mathrm{mg}$ capsule sizes. These size differences result in drug wastage when patients experience serious adverse reactions that require dose reductions, or when patients do not respond to the initial low dose (which is often applied due to high comorbidity burden and low tolerance). Therefore, these patients require dose escalation, as capsules cannot be unwrapped or the previous doses of the drug are taken. However, ribociclib, which has a more flexible dosing pattern, is presumed to reduce the cost of drug wastage. Based on the Markov model and pharmacy acquisition cost model, Biskupiak et al. (65) found that ribociclib dose adjustment did not result in drug wastage. However, palbociclib users experienced drug wastage of $\$ 1,124$ and $\$ 3,727$ per treated patient per year due to dose changes, likely because ribociclib is a $200 \mathrm{mg}$ tablet, and the unused tablets could be administered in subsequent cycles. Another cost analysis by analyzing data from two clinical trials, PALOMA-2 and MONALEESSA-2, also confirmed the advantage of ribociclib in terms of cost per PFS gained (66). In addition, as a research tool to assess drug accessibility, one budget impact analysis in the United States used a cohort-based budget impact model to calculate the incremental cost of introducing ribociclib plus letrozole over three years for American health insurance system (67). The simulation showed that the market share of ribociclib plus letrozole would increase from $3.3 \%$ to $19.3 \%$, and the cumulative total savings with this regimen would be $\$ 3.01 \mathrm{M}$ over three years. The authors recommended that ribociclib plus letrozole may be a cost-saving strategy in the first-line settings. In the future, more budget impact analyses of CDK4/6 inhibitors should be conducted to assess their impact on national health insurance systems to inform drug pricing and increase drug accessibility.

On the other side, we found that current costeffectiveness comparison among different CDK4/6 inhibitors plus endocrine therapy were less published, and only economic evaluations of palbociclib versus ribociclib in first-line treatment on ABC patients were included. As shown in our analysis of the included studies and some conference articles (68-70), ribociclib plus letrozole has better economic benefits than palbociclib plus letrozole for first-line treatment of postmenopausal women with $\mathrm{HR}+$ / HER2- ABC. Therefore, China may consider introducing ribociclib in the future, and the pricing of ribociclib could be adjusted based on two studies conducted from the perspective of the current Chinese healthcare system. Few studies have explored cost-effectiveness of ribociclib or palbociclib under various treatment settings, such as with other endocrine agents, in premenopausal patients or in second- and third-line settings. Further, more studies are still required to demonstrate the economic advantages of ribociclib over palbociclib in different situations.

This article is the first systematic review of the pharmacoeconomic evaluations of CDK4/6 inhibitors plus endocrine therapy for breast cancer. CHEER checklist evaluated the included studies as medium to high quality studies, whose base analysis and sensitivity analyzes were performed for cost and health outcomes. Our review had some limitations: (I) only three studies compared the cost-effectiveness among different CDK4/6 inhibitors, all of which were about the first-line treatment of postmenopausal patients with HR+/HER2- ABC. The small number made the basic analysis less persuasive. Since there is no pharmacoeconomic evaluation of the newly 
marketed CDK4/6 inhibitor abemaciclib, it is impossible to compare its cost-effectiveness with endocrine therapy and two other inhibitors. Thus, the evaluation system among CDK4/6 inhibitors remains incomplete. There is only one pure cost analysis on three CDK4/6 inhibitors (71), which concluded that the economic value of abemaciclib ranked between ribociclib and palbociclib according to the cost per PFS obtained, and the introduction of abemaciclib did not change the cost-effectiveness profile. (II) Several studies did not adjust the inclusion of different costs according to the study perspective. For example, the impact of indirect costs, including loss of labor, on the cost-effectiveness of CDK4/6 inhibitors was not considered from a society-wide perspective. The difference in costs had a significant impact on the results observed in the univariate sensitivity analysis. (III) There is insufficient literature evaluating the economic properties of CDK4/6 inhibitors for different subgroups of target populations, including patients receiving secondline treatment and non-postmenopausal women. As shown in clinical trials, the efficacies of CDK4/6 inhibitors vary in different subgroups in terms of endocrine therapy drug type, metastatic site, age, and race, and consequently, the economic outcomes may also differ remarkably. However, a more detailed analysis is currently impossible due to the small volume of literature. (IV) The studies were conducted in different countries, so there may be heterogeneity among studies in different dimensions, including cost calculation, monetary units, and health preferences, which may impact our conclusions. Most of the included studies were from developed countries, which may be related to the access to CDK4/6 inhibitors.

\section{Conclusions}

In the first-line treatment of postmenopausal patients with advanced HR+/HER2 - breast cancer, the combinations of CDK4/6 inhibitors with letrozole do not offer an economic advantage over letrozole alone, but ribociclib plus letrozole is more cost-effective than palbociclib plus letrozole. The economic impacts of CDK4/6 inhibitors plus endocrine therapy in non-postmenopausal patients or for second-line therapy cannot be fully judged due to the limited number of studies, and it can be speculated from the currently available studies that these strategies are unlikely to be cost-effective. It is recommended that higher-quality, realworld studies and economic evaluations be conducted in the future for CDK4/6 inhibitors in different subgroups of the population, and that the possible impacts of drug price,
HR of PFS and OS, and utility values on the robustness of baseline analysis results be considered in sensitivity analyses. Few economic evaluations of CDK4/6 inhibitors plus endocrine therapy have been carried out in developing countries. For example, a CDK4/6 inhibitor has been marketed in China for only three years, and only a small number of economic evaluations have been conducted. A series of pharmacoeconomic studies should be conducted based on the Chinese health care system to inform price adjustments and health insurance coverage.

\section{Acknowledgments}

Funding: This study was was supported by "Clinical Research Plan of SHDC" (SHDC2020CR3085B to Qing Zhai), Key Innovative Team of Shanghai Top- Level University Capacity Building in Clinical Pharmacy and Regulatory Science at Shanghai Medical College, Fudan University (Shanghai Municipal Education Commission, HJW-R-2019-66-19 to Qiong Du), and Shanghai "Rising Stars of Medical Talent" Youth Development Program, Youth Medical Talents Clinical Pharmacist Program [SHWRS(2020)_087 to Qiong Du].

\section{Footnote}

Reporting Checklist: The authors have completed the PRISMA reporting checklist. Available at https://atm. amegroups.com/article/view/10.21037/atm-21-5110/rc

Conflicts of Interest: All authors have completed the ICMJE uniform disclosure form (available at https://atm. amegroups.com/article/view/10.21037/atm-21-5110/coif). The authors have no conflicts of interest to declare.

Ethical Statement: The authors are accountable for all aspects of the work in ensuring that questions related to the accuracy or integrity of any part of the work are appropriately investigated and resolved.

Open Access Statement: This is an Open Access article distributed in accordance with the Creative Commons Attribution-NonCommercial-NoDerivs 4.0 International License (CC BY-NC-ND 4.0), which permits the noncommercial replication and distribution of the article with the strict proviso that no changes or edits are made and the original work is properly cited (including links to both the formal publication through the relevant DOI and the license). 
See: https://creativecommons.org/licenses/by-nc-nd/4.0/.

\section{References}

1. Sung H, Ferlay J, Siegel RL, et al. Global Cancer Statistics 2020: GLOBOCAN Estimates of Incidence and Mortality Worldwide for 36 Cancers in 185 Countries. CA Cancer J Clin 2021;71:209-49.

2. Babcock A, Ali AA, Balkrishnan R, et al. Real-World Clinical and Economic Outcomes Associated with Palbociclib for HR-Positive/HER2 Negative Metastatic Breast Cancer: A Commentary. J Manag Care Spec Pharm 2020;26:826-31.

3. Eggersmann TK, Degenhardt T, Gluz O, et al. CDK4/6 Inhibitors Expand the Therapeutic Options in Breast Cancer: Palbociclib, Ribociclib and Abemaciclib. BioDrugs 2019;33:125-35.

4. Chong QY, Kok ZH, Bui NL, et al. A unique CDK4/6 inhibitor: Current and future therapeutic strategies of abemaciclib. Pharmacol Res 2020;156:104686.

5. Roskoski R Jr. Cyclin-dependent protein serine/threonine kinase inhibitors as anticancer drugs. Pharmacol Res 2019;139:471-88.

6. Otto T, Sicinski P. Cell cycle proteins as promising targets in cancer therapy. Nat Rev Cancer 2017;17:93-115.

7. Sobhani N, D'Angelo A, Pittacolo M, et al. Updates on the CDK4/6 Inhibitory Strategy and Combinations in Breast Cancer. Cells 2019;8:321.

8. Ortiz AB, Garcia D, Vicente Y, et al. Prognostic significance of cyclin D1 protein expression and gene amplification in invasive breast carcinoma. PLoS One 2017;12:e188068.

9. Spring LM, Wander SA, Zangardi M, et al. CDK 4/6 Inhibitors in Breast Cancer: Current Controversies and Future Directions. Curr Oncol Rep 2019;21:25.

10. Spring L, Bardia A, Modi S. Targeting the cyclin D-cyclindependent kinase (CDK) 4/6-retinoblastoma pathway with selective CDK 4/6 inhibitors in hormone receptorpositive breast cancer: rationale, current status, and future directions. Discov Med 2016;21:65-74.

11. Niraula S. Why upfront use of CDK inhibitors for the treatment of advanced breast cancer may be wasteful, and how we can increase their value. Breast 2019;43:81-4.

12. Husereau D, Drummond M, Petrou S, et al. Consolidated Health Economic Evaluation Reporting Standards (CHEERS)--explanation and elaboration: a report of the ISPOR Health Economic Evaluation Publication Guidelines Good Reporting Practices Task Force. Value
Health 2013;16:231-50.

13. Husereau D, Drummond M, Petrou S, et al. Consolidated Health Economic Evaluation Reporting Standards (CHEERS) statement. Value Health 2013;16:e1-5.

14. Rezapour A, Souresrafil A, Peighambari MM, et al. Economic evaluation of programs against COVID-19: A systematic review. Int J Surg 2021;85:10-8.

15. Galve-Calvo E, González-Haba E, Gostkorzewicz J, et al. Cost-effectiveness analysis of ribociclib versus palbociclib in the first-line treatment of HR+/HER2- advanced or metastatic breast cancer in Spain. Clinicoecon Outcomes Res 2018;10:773-90.

16. Suri G, Chandiwana D, Lee A, et al. Cost-effectiveness analysis of ribociclib plus letrozole versus palbociclib plus letrozole in the United Kingdom. J Health Econ Outcomes Res 2019;6:20-31.

17. Raphael J, Helou J, Pritchard KI, et al. Palbociclib in hormone receptor positive advanced breast cancer: A costutility analysis. Eur J Cancer 2017;85:146-54.

18. Yang J, Han J, Tian M, et al. Cost-Effectiveness of Ribociclib for Hormone Receptor-Positive HER2Negative Advanced Breast Cancer. Cancer Manag Res 2020;12:12905-13.

19. Loke L, Lee SC, Pearce F, et al. Cost-effectiveness of ribociclib as initial treatment for premenopausal women with advanced breast cancer in Singapore. Cancer Rep (Hoboken) 2021;4:e1308.

20. Mamiya H, Tahara RK, Tolaney SM, et al. Costeffectiveness of palbociclib in hormone receptor-positive advanced breast cancer. Ann Oncol 2017;28:1825-31.

21. Matter-Walstra K, Ruhstaller T, Klingbiel D, et al. Palbociclib as a first-line treatment in oestrogen receptorpositive, HER2-negative, advanced breast cancer not costeffective with current pricing: a health economic analysis of the Swiss Group for Clinical Cancer Research (SAKK). Breast Cancer Res Treat 2016;158:51-7.

22. Matter-Walstra K, Schwenkglenks M, Dedes KJ. Costeffectiveness of palbociclib plus letrozole versus letrozole alone as a first-line treatment in women with oestrogen receptor-positive, HER2-negative, advanced breast cancer. Revised results for the Swiss health care setting. Breast Cancer Res Treat 2017;163:635.

23. Mistry R, May JR, Suri G, et al. Cost-Effectiveness of Ribociclib plus Letrozole Versus Palbociclib plus Letrozole and Letrozole Monotherapy in the First-Line Treatment of Postmenopausal Women with HR+/HER2- Advanced or Metastatic Breast Cancer: A U.S. Payer Perspective. J Manag Care Spec Pharm 2018;24:514-23. 
24. Wan X, Zhang Y, Ma J, et al. Ribociclib in hormonereceptor-positive advanced breast cancer: Establishing a value-based cost in China. Breast 2019;43:1-6.

25. Zhang B, Long EF. Cost-effectiveness analysis of palbociclib or ribociclib in the treatment of advanced hormone receptor-positive, HER2-negative breast cancer. Breast Cancer Res Treat 2019;175:775-9.

26. Zhang $\mathrm{Y}$, Zeng X, Deng H, et al. Cost-Effectiveness Analysis of Adding Palbociclib as a Second-Line Endocrine Therapy for HR+/HER2- Metastatic Breast Cancer From the US and Chinese Perspectives. Clin Ther 2019;41:1175-85.

27. Le V, Zhong L, Narsipur N, et al. Cost-effectiveness of ribociclib plus endocrine therapy versus placebo plus endocrine therapy in HR-positive, HER2-negative breast cancer. J Manag Care Spec Pharm 2021;27:327-38.

28. Huang X, Lin S, Rao X, et al. First-line Treatment with Ribociclib plus Endocrine Therapy for Premenopausal Women with Hormone-receptor-positive Advanced Breast Cancer: A Cost-effectiveness Analysis. Clin Breast Cancer 2021. doi: 10.1016/j.clbc.2021.01.019. [Epub ahead of print].

29. Jiang $W$, He Z, Zhang T, et al. Cost-effectiveness analysis of ribociclib plus fulvestrant for hormone receptorpositive/human EGF receptor 2-negative breast cancer. Immunotherapy 2021;13:661-8.

30. Chohan TA, Qayyum A, Rehman K, et al. An insight into the emerging role of cyclin-dependent kinase inhibitors as potential therapeutic agents for the treatment of advanced cancers. Biomed Pharmacother 2018;107:1326-41.

31. Wu Y, Zhang Y, Pi H, et al. Current Therapeutic Progress of CDK4/6 Inhibitors in Breast Cancer. Cancer Manag Res 2020;12:3477-87.

32. Spring LM, Wander SA, Andre F, et al. Cyclin-dependent kinase 4 and 6 inhibitors for hormone receptorpositive breast cancer: past, present, and future. Lancet 2020;395:817-27.

33. Gil-Gil M, Alba E, Gavilá J, et al. The role of CDK4/6 inhibitors in early breast cancer. Breast 2021;58:160-9.

34. Sella T, Weiss A, Mittendorf EA, et al. Neoadjuvant Endocrine Therapy in Clinical Practice: A Review. JAMA Oncol 2021;7:1700-8.

35. Barchiesi G, Mazzotta M, Krasniqi E, et al. Neoadjuvant Endocrine Therapy in Breast Cancer: Current Knowledge and Future Perspectives. Int J Mol Sci 2020;21:3528.

36. Yu KD, Wu SY, Liu GY, et al. Concurrent neoadjuvant chemotherapy and estrogen deprivation in patients with estrogen receptor-positive, human epidermal growth factor receptor 2-negative breast cancer (CBCSG-036): A randomized, controlled, multicenter trial. Cancer 2019;125:2185-93.

37. Nakayama T, Sagara Y, Takashima T, et al. Randomized phase II study of anastrozole plus tegafur-uracil as neoadjuvant therapy for ER-positive breast cancer in postmenopausal Japanese women (Neo-ACET BC). Cancer Chemother Pharmacol 2018;81:755-62.

38. Mohammadianpanah M, Ashouri Y, Hoseini S, et al. The efficacy and safety of neoadjuvant chemotherapy +/letrozole in postmenopausal women with locally advanced breast cancer: a randomized phase III clinical trial. Breast Cancer Res Treat 2012;132:853-61.

39. Sugiu K, Iwamoto T, Kelly CM, et al. Neoadjuvant Chemotherapy with or without Concurrent Hormone Therapy in Estrogen Receptor-Positive Breast Cancer: NACED-Randomized Multicenter Phase II Trial. Acta Med Okayama 2015;69:291-9.

40. Matsunuma R, Watanabe T, Hozumi Y, et al. Preoperative concurrent endocrine therapy with chemotherapy in luminal B-like breast cancer. Breast Cancer 2020;27:819-27.

41. Pernas S, Tolaney SM, Winer EP, et al. CDK4/6 inhibition in breast cancer: current practice and future directions. Ther Adv Med Oncol 2018;10:1758835918786451.

42. Roberto M, Astone A, Botticelli A, et al. CDK4/6 Inhibitor Treatments in Patients with Hormone Receptor Positive, Her2 Negative Advanced Breast Cancer: Potential Molecular Mechanisms, Clinical Implications and Future Perspectives. Cancers (Basel) 2021;13:332.

43. Finn RS, Martin M, Rugo HS, et al. Palbociclib and Letrozole in Advanced Breast Cancer. N Engl J Med 2016;375:1925-36.

44. Hortobagyi GN, Stemmer SM, Burris HA, et al. Updated results from MONALEESA-2, a phase III trial of firstline ribociclib plus letrozole versus placebo plus letrozole in hormone receptor-positive, HER2-negative advanced breast cancer. Ann Oncol 2018;29:1541-7.

45. Slamon DJ, Neven P, Chia S, et al. Phase III Randomized Study of Ribociclib and Fulvestrant in Hormone ReceptorPositive, Human Epidermal Growth Factor Receptor 2-Negative Advanced Breast Cancer: MONALEESA-3.J Clin Oncol 2018;36:2465-72.

46. Tripathy D, Im SA, Colleoni M, et al. Ribociclib plus endocrine therapy for premenopausal women with hormone-receptor-positive, advanced breast cancer (MONALEESA-7): a randomised phase 3 trial. Lancet Oncol 2018;19:904-15. 
47. Goetz MP, Toi M, Campone M, et al. MONARCH 3: Abemaciclib As Initial Therapy for Advanced Breast Cancer. J Clin Oncol 2017;35:3638-46.

48. Slamon DJ, Neven P, Chia S, et al. Overall Survival with Ribociclib plus Fulvestrant in Advanced Breast Cancer. N Engl J Med 2020;382:514-24.

49. Im SA, Lu YS, Bardia A, et al. Overall Survival with Ribociclib plus Endocrine Therapy in Breast Cancer. N Engl J Med 2019;381:307-16.

50. Cristofanilli M, Turner NC, Bondarenko I, et al. Fulvestrant plus palbociclib versus fulvestrant plus placebo for treatment of hormone-receptor-positive, HER2negative metastatic breast cancer that progressed on previous endocrine therapy (PALOMA-3): final analysis of the multicentre, double-blind, phase 3 randomised controlled trial. Lancet Oncol 2016;17:425-39.

51. Turner NC, Slamon DJ, Ro J, et al. Overall Survival with Palbociclib and Fulvestrant in Advanced Breast Cancer. N Engl J Med 2018;379:1926-36.

52. Sledge GW Jr, Toi M, Neven P, et al. MONARCH 2: Abemaciclib in Combination With Fulvestrant in Women With HR+/HER2- Advanced Breast Cancer Who Had Progressed While Receiving Endocrine Therapy. J Clin Oncol 2017;35:2875-84.

53. Sledge GW Jr, Toi M, Neven P, et al. The Effect of Abemaciclib Plus Fulvestrant on Overall Survival in Hormone Receptor-Positive, ERBB2-Negative Breast Cancer That Progressed on Endocrine TherapyMONARCH 2: A Randomized Clinical Trial. JAMA Oncol 2020;6:116-24.

54. Schettini F, Giuliano M, Giudici F, et al. Endocrine-Based Treatments in Clinically-Relevant Subgroups of Hormone Receptor-Positive/HER2-Negative Metastatic Breast Cancer: Systematic Review and Meta-Analysis. Cancers (Basel) 2021;13:1458.

55. Messina C, Cattrini C, Buzzatti G, et al. CDK4/6 inhibitors in advanced hormone receptor-positive/HER2negative breast cancer: a systematic review and metaanalysis of randomized trials. Breast Cancer Res Treat 2018;172:9-21.

56. Spring LM, Zangardi ML, Moy B, et al. Clinical Management of Potential Toxicities and Drug Interactions Related to Cyclin-Dependent Kinase 4/6 Inhibitors in Breast Cancer: Practical Considerations and Recommendations. Oncologist 2017;22:1039-48.

57. Rashid N, Koh HA, Baca HC, et al. Economic burden related to chemotherapy-related adverse events in patients with metastatic breast cancer in an integrated health care system. Breast Cancer (Dove Med Press) 2016;8:173-81.

58. Goyal RK, Cuyun Carter G, Nagar SP, et al. Treatment patterns, adverse events, and direct and indirect economic burden in a privately insured population of patients with $\mathrm{HR}+/ \mathrm{HER} 2$ - metastatic breast cancer in the United States. Expert Rev Pharmacoecon Outcomes Res 2021;21:699-710.

59. Hurvitz S, Guerin A, Brammer M, et al. Investigation of adverse-event-related costs for patients with metastatic breast cancer in a real-world setting. Oncologist 2014;19:901-8.

60. Wong W, Yim YM, Kim A, et al. Assessment of costs associated with adverse events in patients with cancer. PLoS One 2018;13:e0196007.

61. Hansen RN, Ramsey SD, Lalla D, et al. Identification and cost of adverse events in metastatic breast cancer in taxane and capecitabine based regimens. Springerplus 2014;3:259.

62. Sorensen SV, Goh JW, Pan F, et al. Incidence-based costof-illness model for metastatic breast cancer in the United States. Int J Technol Assess Health Care 2012;28:12-21.

63. Li N, Du EX, Chu L, et al. Real-world palbociclib dosing patterns and implications for drug costs in the treatment of HR+/HER2- metastatic breast cancer. Expert Opin Pharmacother 2017;18:1167-78.

64. Dalal AA, Gagnon-Sanschagrin P, Burne R, et al. Dosing Patterns and Economic Burden of Palbociclib Drug Wastage in HR+/HER2- Metastatic Breast Cancer. Adv Ther 2018;35:768-78.

65. Biskupiak J, Oderda G, Brixner D, et al. Quantification of Economic Impact of Drug Wastage in Oral Oncology Medications: Comparison of 3 Methods Using Palbociclib and Ribociclib in Advanced or Metastatic Breast Cancer. J Manag Care Spec Pharm 2019;25:859-66.

66. Giuliani J, Bonetti A. Palbociclib or Ribociclib in FirstLine Treatment in Patients With Hormone ReceptorPositive/Human Epidermal Receptor 2-Negative Advanced or Metastatic Breast Cancer? A Perspective Based on Pharmacologic Costs. Clin Breast Cancer 2019;19:e519-21.

67. Mistry R, Suri G, Young K, et al. Budget impact of including ribociclib in combination with letrozole on US payer formulary: first-line treatment of post-menopausal women with $\mathrm{HR}+/ \mathrm{HER} 2$ - advanced or metastatic breast cancer. Curr Med Res Opin 2018;34:2143-50.

68. Buehler A, Kim HSJ, Fahham L, et al. PCN160 Costeffectiveness of ribociclib plus letrozole compared to palbociclib plus letrozole in the first-line treatment of postmenopausal women with hormone receptor-positive/ 
human epidermal growth factor receptor 2-negative (HR+/HER2-) advanced or metastatic breast cancer $(\mathrm{ABC})$ : a Brazilian private payer perspective. Value Health 2019;22:S466-7.

69. Hettle R, Suri G, Mistry R, et al. PCN119 - CostEffectiveness of Ribociclib Plus Letrozole Versus Palbociclib Plus Letrozole for Postmenopausal Women with Hormone Receptor-Positive (HR+), Human Epidermal Growth Factor Receptor 2-Negative (HER2-) Advanced/Metastatic Breast Cancer from A UK National Health Service Perspective. Value Health 2017;20:A433.

70. Suri G, Mistry R, Young KC, et al. PCN133 - Cost Effectiveness of Ribociclib Plus Letrozole Versus Palbociclib Plus Letrozole for The Treatment of Post-

Cite this article as: Zhu L, Wang M, Luo X, Li H, Shan H, Du Q, Zhai Q. Pharmacoeconomic evaluations of CDK4/6 inhibitors plus endocrine therapy for advanced hormone receptor-positive $(\mathrm{HR}+)$ and human epidermal growth factor receptor-2 negative (HER2-) breast cancer: a systematic review. Ann Transl Med 2022;10(4):233. doi: 10.21037/atm-21-5110
Menopausal Women with Hormone Receptor-Positive (HR+), Human Epidermal Growth Factor Receptor 2-Negative (HER2-) Advanced or Metastatic Breast Cancer from A US Private Third-Party Payer Perspective. Value Health 2017;20:A436.

71. Giuliani J, Bonetti A. The introduction of a third CDK4/6 inhibitor does not change the cost-effectiveness profile in first and subsequent-lines after progression or relapse during previous endocrine therapy in patients with hormone receptor positive ( $\mathrm{HR}+$ )/human epidermal receptor-2 negative (HER-2) advanced or metastatic breast cancer. J Oncol Pharm Pract 2020;26:1486-91.

(English Language Editor: J. Chapnick) 